\title{
Patterns of Molar Wear in Hunter-Gatherers and Agriculturalists
}

\author{
B. HOLLY SMITH \\ Center for Human Growth and Development, The University of Michigan, \\ Ann Arbor, Michigan 48109
}

\author{
KEY WORDS Dental Attrition, Hunter-Gatherers, \\ Agriculturalists
}

\begin{abstract}
Tooth wear records valuable information on diet and methods of food preparation in prehistoric populations or extinct species. In this study, samples of modern and prehistoric hunter-gatherers and agriculturalists are used to test the hypothesis that there are systematic differences in patterns of tooth wear related to major differences in subsistence and food preparation. Flatness of molar wear is compared for five groups of hunter-gatherers $(\mathrm{N}=298)$ and five groups of early agriculturalists $(\mathrm{N}=365)$. Hunter-gatherers are predicted to develop flatter molar wear due to the mastication of tough and fibrous foods, whereas agriculturalists should develop oblique molar wear due to an increase in the proportion of ground and prepared food in the diet.

A method is presented for the quantitative measurement and analysis of flatness of molar wear. Comparisons of wear plane angle are made between teeth matched for the same stage of occlusal surface wear, thus standardizing all groups to the same rate of wear. Agriculturalists develop highly angled occlusal wear planes on the entire molar dentition. Their wear plane angles tend to exceed hunter-gatherers by about $10^{\circ}$ in advanced wear. Wear plane angles are similar within subsistence divisions despite regional differences in particular foods. This approach can be used to provide supporting evidence of change in human subsistence and to test dietary hypotheses in hominoid evolution.
\end{abstract}

Tooth wear is one skeletal feature that preserves direct evidence of the masticatory behavior of mammals. Mastication is intimately related to diet, and patterns of tooth wear can be used to make inferences about diet in prehistoric populations and extinct species. From an anthropological point of view, tooth wear may record important stages in human biological and cultural evolution, including evidence of food resources utilized by ancestral hominids, development of fire and cooking, invention of food processing utilizing grinding tools, adoption of agriculture, invention of pottery, and other refinements in the way food is processed. Microscopic features of wear (Walker et al., 1978; Grine, 1981), rates of tooth wear (Pedersen, 1949), and the form and pattern of tooth wear (Molnar, 1972) may all be informative for studies that seek to reconstruct the diet and methods of food preparation of earlier populations. One pattern that may give evidence on these aspects of human adaptation is the flatness of molar wear.

Since the earliest discoveries of fossil hom- inids, the flatness of molar wear has impressed observers (see Keith and Knowles, 1911-12; Dart, 1929; Clark, 1967). Flat versus oblique molar wear is one of the classic distinctions between hominid and pongid dentitions (Clark, 1955). Although flat wear has been traditionally attributed to canine reduction that allowed a rotary chewing motion, the assumption that tough or fibrous foods are also responsible underlies discussions of hominid or protohominid tooth wear (see Robinson, 1956; Jolly, 1970; Simons, 1976). Changes in food consistency may be the most systematic trend in human food preparation:

Among human beings, the extent to which the process of mechanical food disintegration is done in the mouth, depends inversely on the development of food preparation methods. From primitive man's usage of stone knives, pounding and grinding stones,

Received July 5, 1983; revised September 6, 1983; accepted September 8, 1983 
down through the ages to modern usage of knives, forks, spoons, fast working mincing machines, heavy rolling mills and highly refined foodstuffs, the mechanical disintegration of food has gradually, but surely, been shifted from inside to outside the mouth (Campbell, 1939:53).

A substantial descriptive literature indicates that prehistoric human groups exhibit great variation in tooth wear (e.g., Nicholls, 1914; Campbell, 1925; Leigh, 1925; Rabkin, 1943; Pedersen, 1949). Some investigators have suggested how tooth wear might reflect cultural changes in food preparation (Brace, 1962; Greene et al., 1967; Molnar, 1972; Hinton, 1981).

The adoption of agriculture (or intensive collection and usage of wild grains) probably represents a great change in human food and food preparation. Brace (1962) suggested that the intensive use of grinding stones on grains and the appearance of pottery in the Neolithic are associated with a substantial reduction in food toughness. The change from a hunter-gatherer subsistence to a diet based on ground grains and food cooked in water should produce a reduction in food toughness, fibrousness, and resistence, and thus a reduction in the role of the teeth in breakdown of foods. The product of this change in food consistency, Brace argued, was a change from flat molar wear to a more oblique wear pattern.

This study is an attempt to build an internally consistent model identifying the determinants of one pattern of wear, specifically, the flatness of the occlusal wear plane angle. Samples of prehistoric and modern huntergatherers and agriculturalists for which there is a good archaeological or ethnographic context are used to test the hypothesis that there are communalities in flatness of molar wear related to broad similarities in major food sources and methods of food preparation. Such a broad generalization calls for supporting evidence from a wide-ranging sample of human groups. In this study, the development of molar wear is compared for ten major human groups.

With these broad samples and a quantitative approach to the study of tooth wear, it is possible to investigate a number of longstanding questions: Are there communalities in tooth wear patterns due to similar cultural/technological features of food prepara- tion? How sensitive is a given wear pattern as an indicator of foods and food preparation? How important is a particular food, as compared with its mode of preparation?

\section{MECHANISMS}

Explanation of the mechanism proposed to account for a correspondence between molar wear planes and food consistency requires a brief review of molar wear.

The development of human molar wear is best understood as a modification of a wear pattern common to primates and some other omnivorous mammals. Hominoids, in particular, share a basic wear pattern due to broad similarities in crown morphology, occlusion, and the dynamics of mastication (see Butler, 1973; Mills, 1955). Based on cineradiographic studies of mastication, Hiiemae and associates divided mastication into two cycles, each characterized by a different type of tooth wear (Crompton and Hiiemae 1970; Hiiemae and Kay, 1973; Hiiemae, 1976). In the initial cycle, termed "puncture-crushing," teeth do not contact and repeatedly chop the food bolus, producing blunting wear over the tooth surface. This is followed by a cycle of "chewing" in which teeth shear and grind across each other, producing the characteristic "lingual and buccal phase" wear facets (see Fig. 1 ), well known from the work of Butler (1952, 1973) and Mills (1955). It should be noted that the mandibular buccal and maxillary lingual cusps receive wear on both faces of cusp slopes whereas the remaining cusps wear on one face (Fig. 1, left). As attrition advances, this differential wear tends to produce an oblique surface (Fig. 1, right). An oblique wear plane is the "pattern" expected from near or actual tooth-to-tooth contact in "chewing." "Puncture-crushing," on the other hand, should contribute to wear on the entire crown surface and lead to a flatter wear plane.

The relative amount of "puncture-crushing" required for different foods could influence the obliquity of the wear plane angle. This was first proposed by Taylor (1963), some time before the current terminology appeared:

When tough fibrous foods are prominent in the diet and teeth do not so often make contact during its mastication, there will tend to be less difference in the wear of the buccal and lingual cusps (1963:99). 

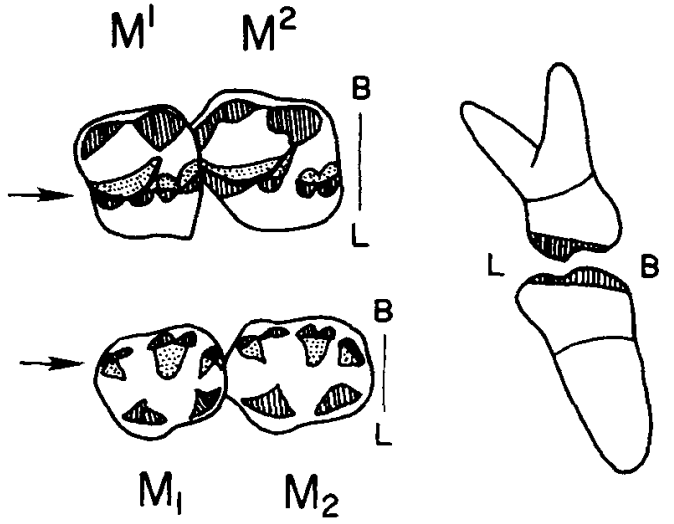

Fig. 1. Development of primate molar wear pattern. At left are maxillary and mandibular first and second molars of a gorilla drawn after Mills (1955). Buccal (B) and lingual $(\mathrm{L})$ directions are indicated. Shaded areas show location of buccal and lingual phase wear facets. Mandibular buccal and maxillary lingual cusps (arrows) receive wear on both faces of cusps whereas remaining cusps wear on one face. As this unequal wear progresses (at right), molar surfaces develop obliquely angled wear planes.

Animal experiments indicate that the period of "puncture-crushing" can be significantly increased for "tough" foods (Hiiemae, 1976). This explanation predicts that more highly oblique wear results from more mechanically refined foods.

A second mechanism that could produce the same effect can be proposed. First, a wider mandibular movement creates more even wear across buccal and lingual cusps. Secondly, mandibular movement responds to food consistency: tougher or more fibrous foods are chewed with a wider lateral excursion of the mandible. Thus tough foods also contribute indirectly to flatter molar wear.

This hypothesis, in its entirety, is difficult to attribute to any one individual. The notion that canine reduction allows a more "rotary" chewing motion that creates flat wear is found in early discussions of fossil hominids (Keith and Knowles, 1911-1912). The fraudulent flat wear on the Piltdown molars placed this feature in the limelight at an early date. Reduced canines and flat wear subsequently became an accepted cause and effect (Keith, 1913; Gregory, 1922; Schultz, 1925; Gregory et al., 1938). Most discussions seem to assume that a "rotary" type of mastication is necessary for a hard or tough diet, although this is not always clearly stated (Dart, 1929; Clark, 1955; Robinson, 1954, 1956; Simons, 1968, 1976; Jolly, 1970).

Scattered references to the effect of food consistency on mandibular motion can be found in the dental literature (Black, 1895; Pickerill, 1923; Leigh, 1925) and this has been the subject of experimental work. Studies that have traced human mandibular movement typically find markedly different responses to different test foods:
Tough food usually is associated with grinding strokes with pro- nounced lateral deflexion of the mandible, whereas soft food pro- duces more vertical, chopping movements (Ahlgren 1976:127).

Nearly all treatments of the subject, whether experimental or descriptive, simply use the word "tough" as the quality of food under consideration. Vague as it is, this represents the status of the model. Until there are more efforts at defining the properties of foods and their effect on mastication, we are relegated to a comparison of "tough", "resistant," or "fibrous" foods with "refined" or "soft" foods. The direct "puncture-crushing" hypothesis and the indirect "mandibular movement" hypothesis both predict that tough and fibrous foods produce flatter wear. They are not exclusive mechanisms, and both may operate simultaneously.

\section{REVIEW OF MATERIALS}

A series of five, clear-cut agriculturalists from a variety of environments were chosen for study: Neolithic Europeans, prehistoric and early historic Nubians, early historic British, Mississippian American Indians, and Puebloan American Indians. Hunter-gatherers are represented by a Middle and Upper Paleolithic sample from Europe and the Near East, a Mesolithic sample from France, Archaic American Indians, recent Australian aborigines, and precontact Canadian and Alaskan Eskimos. In most cases these human "groups" were created by combining material from several neighboring sites or subperiods. Groups and their sub-member sets are listed in Table 1 , with brief references to background information. All mater- 
TABLE 1. Classification and summary of study sample, with periods or approximate dates, and references

\begin{tabular}{|c|c|c|c|}
\hline $\begin{array}{l}\text { Group } \\
\text { site/sub-group }\end{array}$ & Period/Date & Number & Reference $^{1}$ \\
\hline \multicolumn{4}{|c|}{ Hunter-gatherers } \\
\hline $\begin{array}{l}\text { Paleolithic } \\
\text { Western Europe } \\
\text { Levant } \\
\text { France }\end{array}$ & $\begin{array}{l}\text { Middle paleolithic }{ }^{2} \\
\text { Middle-transitional }^{3} \\
\text { Upper paleolithic }^{4}\end{array}$ & $\begin{array}{r}6 \\
7 \\
14\end{array}$ & $\begin{array}{l}\text { Oakley et al., } 1971 \\
\text { " }\end{array}$ \\
\hline \multicolumn{4}{|l|}{ Mesolithic (France) } \\
\hline Hoëdic & ca $6570 \mathrm{BP}$ & 7 & Péquart and Péquart, 1934 \\
\hline Téviec & ca $6570 \mathrm{BP}$ & 8 & Péquart et al., 1937 \\
\hline Baume de Montclus & $\mathrm{ca} 6000 \mathrm{BP}$ & 1 & Ferembach, 1974a \\
\hline Rochereil & ca $7000 \mathrm{BP}$ & 1 & Ferembach, 1974b \\
\hline \multicolumn{4}{|l|}{ Australian } \\
\hline South Australia & pre-1900 & 32 & (University of Edinburgh) \\
\hline New South Wales & $"$ & $\begin{array}{r}26 \\
9\end{array}$ & $"$ \\
\hline Victoria & $"$ & 6 & $"$ \\
\hline West Australia & $"$ & 4 & $"$ \\
\hline \multicolumn{4}{|l|}{ Eskimo } \\
\hline $\begin{array}{l}\text { Thule (Canada) } \\
\text { Point Hope (Alaska) }\end{array}$ & $\begin{array}{l}\text { ca } 1200 \mathrm{AD} \\
\text { pre-contact }\end{array}$ & $\begin{array}{l}58 \\
20\end{array}$ & $\begin{array}{l}\text { Merbs, } 1968 \\
\text { (Smithsonian) }\end{array}$ \\
\hline \multicolumn{4}{|l|}{ Archaic } \\
\hline LU 25 (Alabama) & $\geqslant 4700 \mathrm{BP}$ & 46 & $\begin{array}{l}\text { Webb and DeJarnette, } \\
1942\end{array}$ \\
\hline \multirow[t]{2}{*}{ Subtotal } & \multicolumn{3}{|c|}{ A criculturalists } \\
\hline & & & \\
\hline $\begin{array}{l}\text { Neolithic Europe } \\
\text { British }\end{array}$ & Neol & 15 & Duc \\
\hline $\begin{array}{l}\text { Dolmen de Sauveterre } \\
\text { (France) }\end{array}$ & ca $1400-1000 \mathrm{BC}$ & 15 & Prunières, 1873 \\
\hline \multicolumn{4}{|l|}{ Nubian } \\
\hline A-Group & ca $3300-2800 \mathrm{BC}$ & 28 & Nielsen, 1970 \\
\hline C-Group & ca $2300-1800 \mathrm{BC}$ & 42 & $"$ \\
\hline Pharaonic & ca $1800-1200 \mathrm{BC}$ & 7 & $"$ \\
\hline Meroitic & ca AD $0-350$ & 41 & $"$ \\
\hline X-Group & ca AD $350-550$ & 33 & $"$ \\
\hline Christian & ca AD 550-1000 & 11 & " \\
\hline C-, X-, or Meroitic & ca 2300 BC-AD 350 & 13 & $"$ \\
\hline \multicolumn{4}{|l|}{ Historic British } \\
\hline Maiden Castle & Iron Age, $\mathrm{AD} 42-47$ & 26 & Wheeler, 1940 \\
\hline Poundbury & Iron Age & 30 & Green, 1974 \\
\hline Burwell & Anglo-Saxon & 24 & Brash et al., 1935 \\
\hline Comet Place & $\begin{array}{l}\text { Medieval, ca AD } \\
1300\end{array}$ & 25 & (Cambridge University) \\
\hline \multicolumn{4}{|l|}{ Mississippian } \\
\hline LU 25 (Alabama) & ca AD $1200-1500$ & 23 & Webb and DeJarnette, \\
\hline MS 80 (Alabama) & $\geqslant \mathrm{AD} 1000$ & 32 & $\begin{array}{l}1942 \\
\text { Webb and Wilder, } 1951\end{array}$ \\
\hline $\begin{array}{l}\text { Puebloan } \\
\text { Gran Quivira (New Mexico) }\end{array}$ & \\
\hline Subtotal & & 365 & \\
\hline Total & & 663 & \\
\hline
\end{tabular}

${ }^{\text {I}}$ Reference given for publications about particular site, dates may come from other sources (see Smith, 1983a). Location of collection given if no publication is available.

2 Sites: Montmaurin, La Ferrasie, La Quina, Gibraltar.

${ }^{3}$ Sites: Tabun, Skhul, Qafzeh.

${ }^{4}$ Sites: Cro-Magnon, St. Germaine-la-Rivière, Grotte d'Isturitz, Abri Pataud, Abri Lachaud, Laugerie-Basse. 
ial is in research/museum collections in the United States and Europe. ${ }^{1}$

The hunter-gatherers probably span greater diversity in food preparation and food sources than do the agriculturalists. Australian aborigines, for example, used grinding stones to produce a grass seed cake (these cakes have been described as "hard as a brick" [Nicholls, 1914]). This practice was unavailable to Eskimos, who, however, did boil meat in stone bowls over lamp flames (see Jenness, 1922). Raw, frozen, or dried meat also formed a major part of Eskimo diets by most accounts (Thalbitzer, 1914; Jenness, 1922; de Poncins, 1941). Although the five groups of hunter-gatherers subsisted on a variety of plant and animal foods, none had pottery and none are thought to have had a diet primarily based on ground grains; even grinding stones are absent in some groups. In contrast, the five agriculturalist groups are known to have made extensive use of grinding stones to grind some grain crop, and to have used water-tight, fire-resistant containers (pottery) to cook food for long periods in water. An overview of the diet and food preparation of the ten human groups analyzed here can be found in Smith (1983a).

There is some independent, skeletal evidence of a difference in foods. Caries frequency is a good indicator of the approximate amount of processed carbohydrates in the diet (see Hardwick, 1960; Moore and Corbett, 1978; Turner, 1979). Caries frequency is near zero in the five groups of hunter-gatherers, and substantial in the five groups of agriculturalists, supporting the proposed differences in proportion of processed grains in the diets of hunter-gatherers and agriculturalists (exact frequencies cannot be given since extreme pathologies, including cases of ad-

\footnotetext{
'Sources of material: Neolithic Europe, Duckworth Laboratory of Physical Anthropology, Cambridge University, and the Musée de l'Homme; Nubians, Laboratory of Physical Anthropology, The University of Copenhagen, and University of Chicago collection in the care of Dr. Charles Merbs of Arizona State University; historic British, British Museum (Natural History), and Duckworth Laboratory, Cambridge University; Mississippian American Indians, collections of the Alabama Museum of Natural History on loan to the University of Alabama; Puebloan American Indians, Gran Quivira National Monument collection on loan to Dr. Christy Turner at Arizona State University; Skhul V, Harvard Peabody Museum, Harvard University; Middle and Upper Paleolithic, British Museum (Natural History), Musée de l'Homme, and Institut de Paléontologie Humaine; Mesolithic, Institut de Paléontologie Humaine; Archaic American Indians, collections of the Alabama Museum of Natural History on loan to The University of Alabama; Australian aborigines, University of Edinburgh Medical School, Department of Anatomy; Thule Eskimos, Canada National Museum of Man collection on loan to Dr. Charles Merbs at Arizona State University; Alaskan Eskimos, Smithsonian Institution.
}

vanced caries, were eliminated from study).

By all evidence, both hunter-gatherers and agriculturalists had an abrasive diet. Rate of wear alone (studied using chronological age estimates) will not differentiate them. The dry, sandy environment of the agriculturalist Nubians, for example, apparently led to a rate of wear as high as that of Australian aborigines and Archaic American Indians. Patterns of tooth wear may be sensitive to differences in food consistency that are less affected by local environmental factors. Since it is not possible to prove a difference in food consistency between the two subsistence groups (in the sense of measurements of the toughness of native foods), this study must instead build an internally consistent model of the correspondence of tooth wear and subsistence.

Samples were purposely chosen to cross-cut a variety of specific environments, particular foods, and craniofacial forms to minimize the chance that observed differences in tooth wear are merely reflections of idiosyncracies of particular people, places, and times. Paradoxically, tooth wear is of little use for a synthetic understanding of diet and mastication if it is either completely nonspecific or so specific that it is idiosyncratic. This study was designed to determine if there are communalities in molar wear related to broad levels of subsistence or food preparation that overcome regional factors.

\section{METHODS}

Differential buccal and lingual wear is viewed as a continuum that may be altered or modified in degree, but not categorically changed by food consistency. Compilation of discrete data on the location of wear has not proven to be productive (e.g., Zuckerman, 1954; Gantt, 1979). In this study, the angle of the occlusal wear plane surface relative to a horizontal occlusal plane was measured with a modified protractor (see Fig. 2), similar to instruments used by Butler (1972) and Hall (1977). Angles were recorded to the nearest $0.5^{\circ}$. Slopes to the buccal (as in Fig. 2) are arbitrarily designated as positive and slopes to the lingual are designated negative. Wear plane angles are measured on occluding surfaces on upper and lower teeth: on the talonid basin of mandibular molars and across the trigone of maxillary molars. These are the primary crushing cusps and basins, which are also the areas of greatest wear. Unworn teeth are measured from cusp to cusp, not from cusp to fossa. Both teeth must 


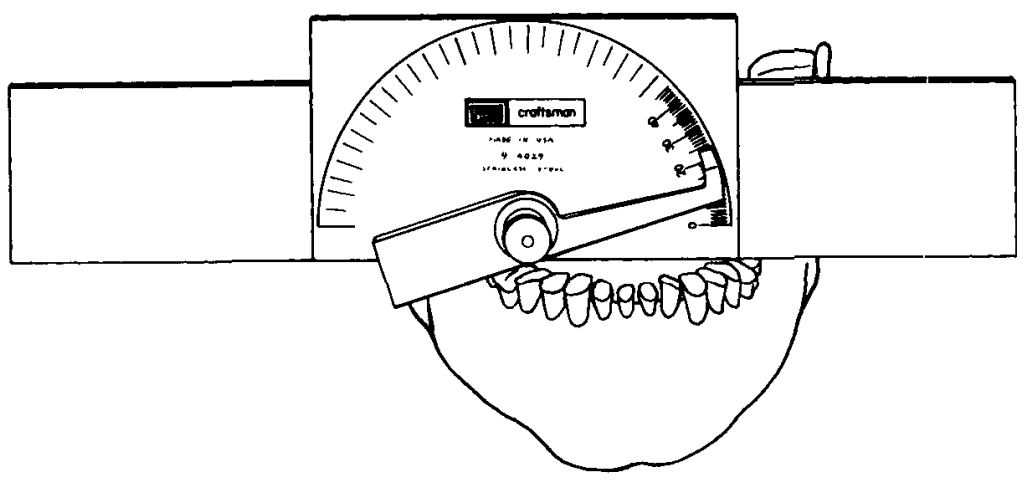

Fig. 2. Instrument used to measure occlusal wear plane angles, constructed by mounting a Sears Roebuck and Co. metal protractor no. $9-4029$ on a straight edge. Metal pieces were added to the straight edge to make the arms flush with the protractor face. The instrument is centered on highest point on the molar talonid (or trigone) and the far arm is placed on the homologous point on the antimere. The bar is brought down across the occlusal surface and the pointer indicates the angle of deviation of the crown surface from a horizontal de fined by the base of the instrument. This mandible has a wear plane angle of $17^{\circ}$ to the buccal on the first molar. be in place in bone, and teeth partly extruded from their sockets during life, obviously dislocated, or virtually destroyed by dental caries cannot be measured.

Wear plane angles in the study sample showed a total range of more than $80^{\circ}$, from $-30^{\circ}$ to $+34^{\circ}$ in the mandible, and from $-43^{\circ}$ to $+41^{\circ}$ in the maxilla. Remeasurement of wear plane angles for 247 teeth showed good replicability. Approximately $70 \%$ of errors (deviation from original measurement) were within $\pm 1.0^{\circ}$, and $80 \%$ were within $\pm 1.5^{\circ}$ of the original measurement.

The goal of the analysis was to compare development of wear plane angles independently of population differences in rates of overall wear of the occlusal surface. Therefore all populations were standardized to the same rate of wear by studying wear plane angles by stage of wear rather than by chronological age. This analysis is concerned with the angle of wear at some stage $\mathrm{x}$, regardless of whether this stage occurs at age 20 or 30 years.

Amount of molar wear has traditionally been scored on an ordinal scale (Broca, 1879), and more than a dozen such scales appeared in the literature from about 1930 to 1980 . A pilot study using different scales indicated that the best system for this study was the eight-stage system of Murphy (1959b, see also 1959a). His system, however, was based on his experience with Australian aborigines, and it created difficulties when used on American Indian test samples. Murphy's scale was modified to make it more widely applicable to a variety of human groups; stages were altered in scope and more pattern variability was anticipated. A preliminary version of this scale was developed in cooperation with R. Hinton (see Hinton, 1981). The present version, fully described in Table 2 and illustrated in Figure 3, differs in some details. Only the molar scale is used here. Replicability is about $90 \%$ for molars and declines to about $85 \%$ for teeth that are simpler in form, based on an error study involving $N=1000$ rescores. Errors of more than one stage are rare or nonexistent after some practice with the system. To date, the molar wear scale seems to be applicable to a wide variety of human groups, pongids, and even to omnivorous fossil mammals. Special scales must be designed for teeth quite different in form and function (e.g., pongid canines).

This analysis presents data for the right side, using left side values only when a right side tooth was damaged. Use of one side or another is preferable to a.veraging sides when an ordinal variable (wear stage) is involved. Since there can be considerable asymmetry in tooth wear, a right $M_{1}$ wear stage was never paired with a left $\mathrm{M}_{1}$ angle, etc.

Dental pathologies were noted and taken into account in all analyses. At least 16 scorable teeth per dentition were required for inclusion in the study (less than 16 were allowed for Paleolithic specimens since mate rial is limited and pathologies are rare). This cut-off was based on the reasonable assumption that individuals who have lost about 
TABLE 2. Descriptions of stages of occlusal surface wear

Molars

0 . Missing or cannot be coded

1. Unworn to polished or small

facets (no dentin exposure)

2. Moderate cusp removal (blunting). Thinly enamelled teeth (human deciduous molars, chimpanzee molars) may show cusp tip dentin but human permanent molars show no more than one or two pinpoint exposures

3. Full cusp removal and/or some dentin exposure, pinpoint to moderate

4. Several large dentin exposures, still discrete

5. Two dentinal areas coalesced

6. Three dentinal areas coalesced, or four coalesced with enamel island

7. Dentin exposed on entire surface, enamel rim largely intact

8. Severe loss of crown height, breakdown of enamel rim; crown surface takes on shape of roots
Premolars

0 . Missing or cannot be coded

1. Unworn to polished or small facets (no dentin exposure)

2. Moderate cusp removal (blunting)

3. Full cusp removal and/or moderate dentin patches

4. At least one large dentin exposure on one cusp

5 . Two large dentin areas (may be slight coalescence)

6. Dentinal areas coalesced, enamel rim still complete

7. Full dentin exposure, loss of rim on at least one side

8. Severe loss of crown height; crown surface takes on shape of roots
Incisors and canines

0 . Missing or cannot be coded

1. Unworn to polished or small facets (no dentin exposure)

2. Point or hairline of dentin exposure

3. Dentin line of distinct thickness

4. Moderate dentin exposure no longer resembling a line

5. Large dentin area with enamel rim complete

6. Large dentin area with enamel rim lost on one side or very thin enamel only

7. Enamel rim lost on two sides or small remnants of enamel remain

8. Complete loss of crown, no enamel remaining; crown surface takes on shape of roots half their teeth to painful, infectious disease do not have normal patterns of mastication. Dropping out all pathologies, on the other hand, would limit inference to a highly restricted subset of the population, and eliminate most old individuals in some populations. Pathologies in remaining dentitions were classified by level of severity, and tested for systematic effects. Dentitions with several major carious lesions and/or abscesses, severe and widespread periodontal destruction, or several molars lost antemortem were deemed "pathological." Separate analyses of wear plane angles were performed both with and without these dentitions for each of the ten human groups. Remarkably, removal of "pathological" dentitions amounting to as much as $20 \%$ of the total sample has almost no effect on results, even though this also preferentially removes old individuals. Thus, there is no reason to believe that the more disease- or caries-prone individuals in any group have systematically (directionally) different wear plane angles, or that pathologies per se produce observed between-group differences. It should be realized, however, that as all dental tissues break down in terminal wear stages, extreme variants can occur.

Parametric statistics are used in the analysis of the relationship of wear plane angle to stage of wear. Stage of wear is the independent variable ( $x$ ) and angle of the occlusal surface is the dependent variable $(y)$ in regression analysis. This method of analysis can be justified on several grounds. Increas- ing wear is, logically, an independent variable, i.e., the cause of change in wear plane angle. Using stage of wear as a categorical variable ignores the inherent ordered relationship of one stage to the next and does not make full use of the data. Although only an ordinal variable, eight stages of wear provide some approximation to the underlying continuous phenomenon. Error in the $\mathrm{x}$ variate does not demand a major axis fit if error is uncorrelated with x (Sokal and Rohlf, 1969), a condition that is fulfilled here. Least squares regression assumes that there is a normal distribution in $\mathrm{y}$ for every $\mathrm{x}$. This assumption is satisfied in these data, however they do not make a good approximation to a bivariate normal distribution as required for a major axis fit. Finally, development of wear plane angle with stage of wear appears to be approximately linear (see Fig. 4). Small deviations are not critical if the same range in $\mathrm{x}$ is compared in each regression. Even so, individual means and tests not assuming linearity are also provided and ultimate conclusions do not depend on a strictly linear model.

\section{RESULTS}

The full data set for wear plane angle of the mandibular first molar organized by stage of wear appears in Figure 4, with agriculturalists at left and hunter-gatherers at right in each paired column. Several features of wear plane angle development are univer. sal and do not depend on subsistence group. 


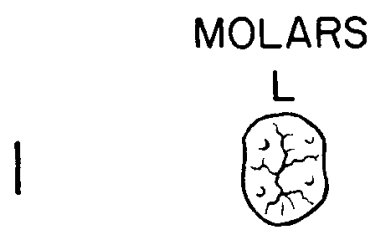

\section{PREMOLARS}

U<smiles>c1ccccc1</smiles>

INCISORS \& CANINES $\mathrm{U}$<smiles>C1CCC1</smiles><smiles></smiles>

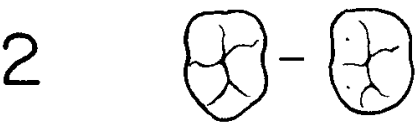<smiles>[C-]1C=CC=C1</smiles><smiles>[CH]</smiles><smiles>C1=CC=C1</smiles><smiles></smiles><smiles>C1=CC([c-]2cccc2)C=C1</smiles><smiles>C1=CC1</smiles><smiles>[C]1C=CC=C1</smiles><smiles>c1ccc(-c2ccccc2-c2ccccc2)cc1</smiles><smiles></smiles><smiles>[CH-]</smiles><smiles>C1=CC1</smiles>

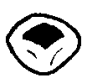

岁
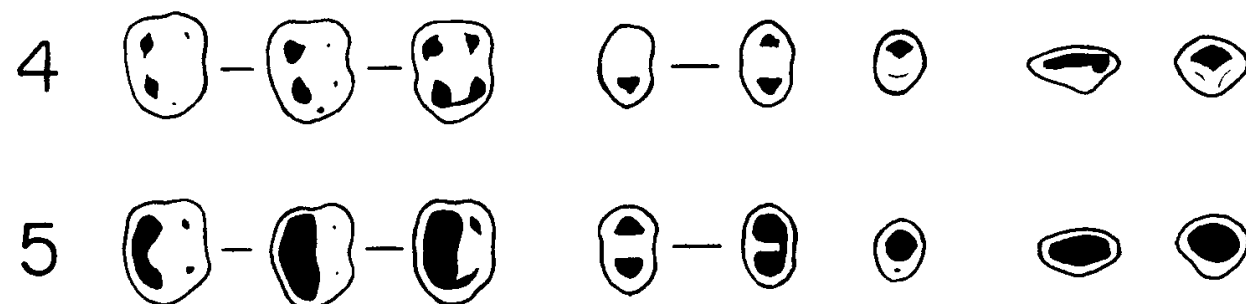

$\stackrel{1}{5}$
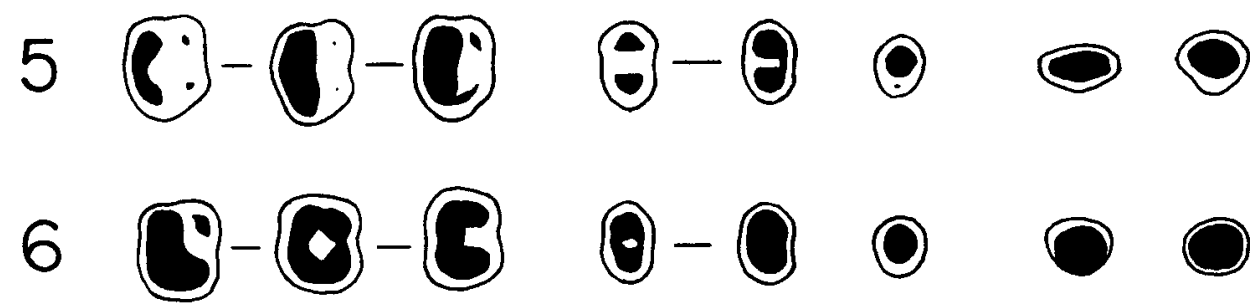<smiles>[3H]</smiles>
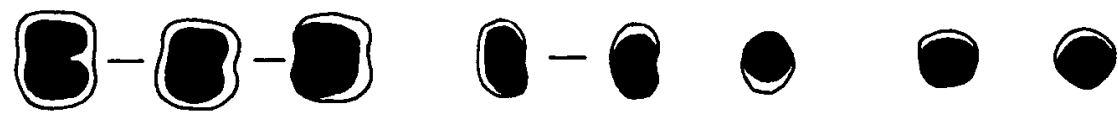

8

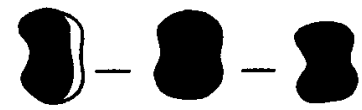

Fig. 3. Diagrams of crown surfaces used to score stages of tooth wear (matched to descriptions in Table 2). Bars between outlines connect common variants of pattern and degree of wear allowed in a stage. Abbreviations $L$ (lower) and $U$ (upper) designate the arch used in the prototype. There is no difficulty applying prototypes for

First molars erupt with a lingual orientation of the crown (negative occlusal surface angle). This is typical of mandibular molars, which show increasingly severe lingual inclinations from mesial to distal molars (Dempster et al., 1963). Wear, typically concen-

trated on the buccal half of mandibular crowns to some degree, tends to flatten the occlusal surface angle and finally to reverse it. This is a good explanation for the confusing reports of both flat arid oblique wear in a single human group (see Rabkin, 1943;

one arch to the other except in the case of premolars, where examples for each are given. Borderline judgments at stages 1-3 should be based on cusp removal, and at stages 4-8, proportion of dentin versus enamel on the crown.

$$
\text { single human group (see Rabkin, 1943; }
$$


Moses, 1946). Since an individual tooth may change in angle some $15-30^{\circ}$ in a lifetime, variance is quite large if age (or wear stage) is ignored.

When occlusal plane angle is sorted by stage of wear, differences in central tendency of the two subsistence groups can be seen, even though ranges and standard deviations are high when sorted by only eight stages. Table 3 summarizes mean wear plane angles for agriculturalists and hunter-gatherers. At wear stages 1 and 2 the two groups are not significantly different, suggesting that angles of eruption of first molars are not widely different (note that sample sizes become adequate at stage 2). All subsequent comparisons indicate that wear planes are significantly different at comparable wear stages (the more conservative two-tailed $p$ values are reported throughout although one-sided tests would be appropriate since the direction of difference has been predicted). Agriculturalists develop higher angles than hunter-gatherers, ultimately reaching a $10^{\circ}$ difference in high wear.

At stage 8 , the severely-angled remnant of the crown tends to fracture in agriculturalists, but not in hunter-gatherers. This is probably because agriculturalists often develop deeply cupped-out dentin that further weakens the tooth. Hunter-gatherers do not show cupping to this degree, and molar wear plane angle continues to increase at stage 8 wear. Recent experimental evidence suggests that cupping results from the presence of fine particles in food (see Costa and Greaves, 1981). Cupping itself may be a sign of processing grains with grinding stones, in which grains are reduced to fine particles and fine particles of stones are introduced into food. This differential stage of fracture does not affect the analysis to a great degree since few relatively healthy dentitions can

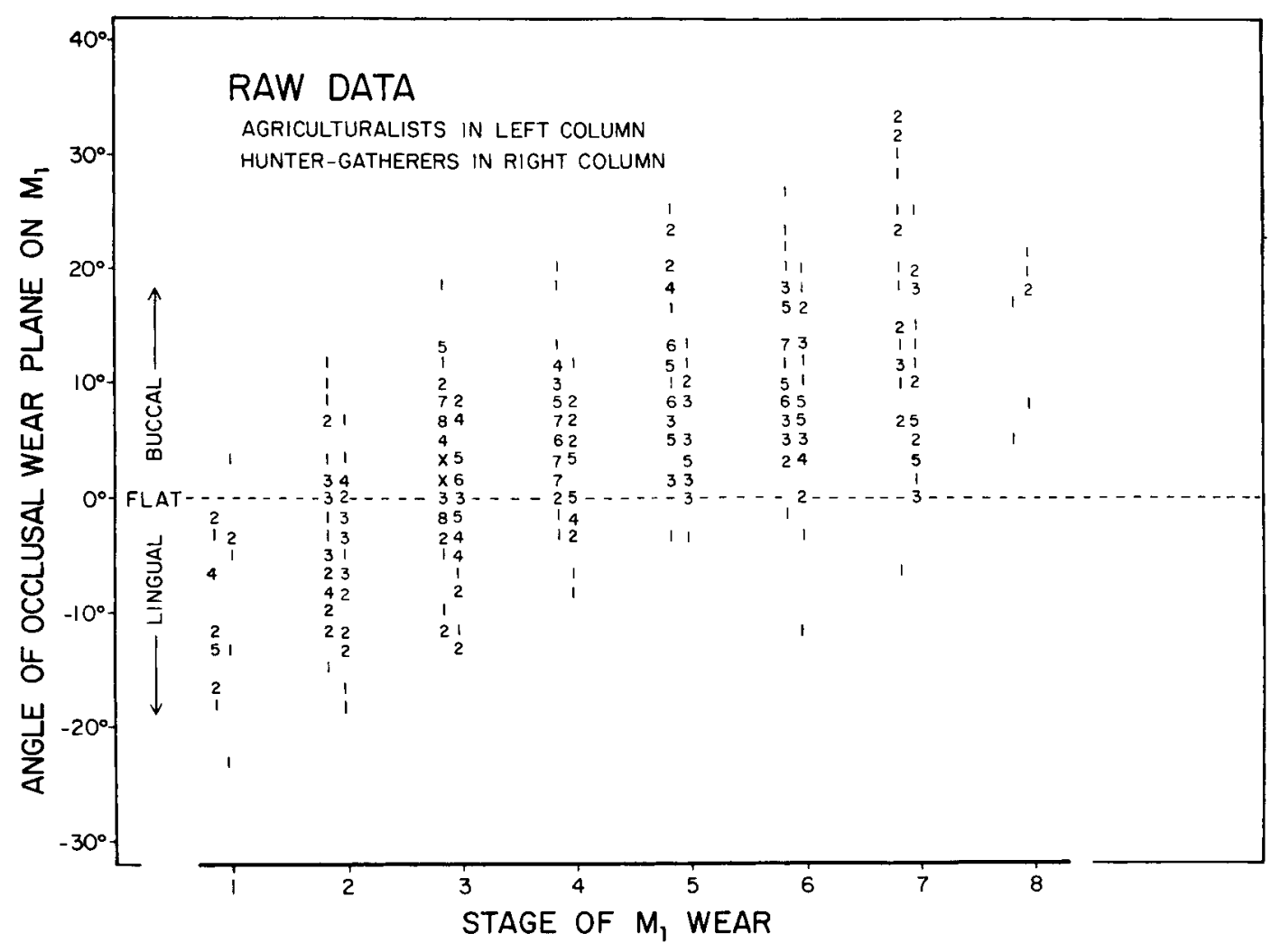

Fig. 4. Raw data for human $\mathrm{M}_{1}$ wear plane angle (ordinate) at each stage of wear (abscissa). Wear plane angles for agriculturalists are at left and hunter-gatherers at right in each paired column. Numbers indicate $\mathrm{N}$ at each point and $\mathrm{X}$ stands for $\mathrm{N} \geqslant 10$. The dotted line indicates a perfectly flat $\left(0^{\circ}\right)$ surface. Note that wear causes a change in angle from lingual to buccal, and that the relationship between wear plane angle and stage of wear is approximately linear. 
TABLE 3. Student's t-tests comparing $M_{l}$ wear plane angle at each stage of wear for agriculturalists versus hunter-gatherers

\begin{tabular}{|c|c|c|c|c|c|c|c|c|}
\hline \multirow{3}{*}{$\begin{array}{l}\text { Wear } \\
\text { stage }\end{array}$} & \multicolumn{7}{|c|}{$\mathrm{M}_{1}$ Wear plane angle } & \multirow[b]{3}{*}{$\mathrm{p}$} \\
\hline & \multicolumn{3}{|c|}{ Agriculturalists } & \multicolumn{3}{|c|}{ Hunter-gatherers } & \multirow{2}{*}{$\begin{array}{c}\text { Mean } \\
\text { difference }{ }^{1}\end{array}$} & \\
\hline & Mean & S.D. & $\mathrm{N}$ & Mean & S.D. & $\mathrm{N}$ & & \\
\hline 1 & -10.3 & 5.3 & 17 & -6.5 & 10.2 & 5 & -3.8 & .273 \\
\hline 2 & -2.8 & 7.1 & 28 & -5.0 & 6.6 & 26 & 2.3 & .230 \\
\hline 3 & 3.6 & 5.5 & 72 & -0.9 & 5.6 & 39 & 4.5 & .001 \\
\hline 4 & 5.7 & 4.7 & 46 & 1.5 & 4.8 & 25 & 4.2 & .001 \\
\hline 5 & 11.1 & 6.8 & 40 & 4.1 & 4.1 & 21 & 6.9 & .001 \\
\hline 6 & 11.9 & 5.9 & 40 & 7.4 & 6.5 & 31 & 4.5 & .003 \\
\hline 7 & 18.7 & 10.6 & 21 & 8.9 & 7.3 & 27 & 9.8 & .001 \\
\hline 8 & - & - & 2 & - & - & 5 & - & - \\
\hline
\end{tabular}

'Agriculturalist minus hunter-gatherer' value, in degrees.

be found to measure at this stage of wear in any group. Dentin cupping itself does not alter the measurement of angle of wear before enamel borders fracture.

Sample sizes at each wear stage are insufficient to compare means for each of the ten human groups. Comparisions of individual groups are based on least squares regression lines projected through available data (see Fig. 5). Agriculturalists (solid lines) and hunter-gatherers (broken lines) are intermixed at stage 1 , indicating no systematic difference in orientation of unworn crowns. Lines begin to separate about stage 3 and do not overlap subsequently; by stages $5-8$ central tendencies are quite distinct. The tightly clustered lines representing agriculturalists are above all hunter-gatherers, showing the development of oblique wear planes in the former. Hunter-gatherers, except the Paleolithic sample, also appear to be quite similar. The Paleolithic stands out from other groups, appearing to maintain the flattest wear. This is intriguing since one would expect the heaviest demands to have been placed on the dentition in the Paleolithic, but unfortunately, a sample size of ten is insufficient to confirm this difference statistically. ${ }^{2}$ Huntergatherers have relatively flat, even wear across the crown surface that leads to a low rate of change in the occlusal surface angle. No group shows wear that is perfectly flat with respect to the tooth axis; this would lead to a steadily maintained angle of about $-5^{\circ}$.

Table 4 documents least squares lines and statistical tests for regression lines shown in Figure 5. Individual slopes are significantly different from zero, confirming that stage of

${ }^{2}$ Paleolithic specimens in $\mathrm{M}_{1}$ analysis include: Montmaurin Tabun I, Skhul V, Abri Pataud, Abri Lachaud 3 and 5, LaugerieBasse, St. Germaine-La-Rivière B1, B3, and B4 wear and wear plane angle are related. Regression slopes are directly interpretable as degrees of change in angle per stage of wear. Rates of change are generally higher in agriculturalists (3.4-5.3 $3^{\circ}$ per wear stage) than in hunter-gatherers $\left(1.9-3.5^{\circ}\right.$ per wear stage). ${ }^{3}$ Analysis of covariance was used to determine if slopes and overall regression lines are significantly different. The five agriculturalist regression lines cannot be distinguished statistically and may therefore be described by a single line with a slope of 4.0 (intercept of $10.2^{\circ}$ ). Similarly, the huntergatherers overall have a single line with a slope of 2.9 (intercept of $10^{\circ}$ ). The five hunter-gatherers seem to be less homogeneous than the agriculturalists, and slightly larger samples might confirm this statistically. Overall slopes of regressions (rates of change) for the two subsistence categories are significantly different from each other at $\mathrm{p}<.001$. Agriculturalists develop angles some $8-10^{\circ}$ higher than hunter-gatherers in advanced wear stages. The difference in angle at stage 7 predicted fiom least squares lines $\left(8^{\circ}\right)$ is quite close to the actual mean difference $\left(10^{\circ}\right)$. Statistical confirmation is not dependent on a linear model; trends are clear enough that a simple sign test based on individual means of the ten human groups supports the hypothesis that agriculturalists develop more oblique wear than huntergatherers $(\mathrm{p}<.05)$.

At first molars, the overall difference in rate of change is about $1^{\circ}$ per stage of wear. Although this may seem to be minor, the magnitude of the difference can be consider-

\footnotetext{
${ }^{3}$ The Eskimo regression line is pulled up sharply because of an extreme lingual orientation of unworn crowns; final wear planes are quite flat. Eskimo dental arch morphology is different enough to strain the limits of this simple linear model.
} 
able in advanced wear. When teeth are matched for stage of wear, the differences in wear plane angle of molars of hunter-gatherers and agriculturalists are visible to the eye (see Fig. 6).

Analyzed in this fashion, wear plane angle appears to be sensitive to major differences in food and food preparation. With large samples it should be sensitive to finer gradations of change in foods and methods of preparation. If so, a time trend might be visible in the Nubian sample since it is of moderate size and spans several periods thought to show increases in the intensity of agriculture (see Carlson and Van Gerven, 1979). Figure 7 shows regression lines for $\mathrm{M}_{1}$ wear plane angle for A-Group, C-Group, and X-Group plus
Meroitic (combined since they each span a relatively short time). Pharaonic and Christian are omitted because sample size is less than eight individuals. Least squares lines for all groups are still above lines for huntergatherers (shaded region), although individual data points overlap. The early A-Group, thought to have a more mixed economy, is perfectly intermediate between other more clear-cut hunter-gatherers and agriculturalists. There is a distinct trend toward more oblique wear in more recent groups paralleling decreases in craniofacial robusticity through time described by Carlson (1976) for this same sample. Trends in tooth wear and craniofacial robusticity could both be responses to an increasing reliance on ground

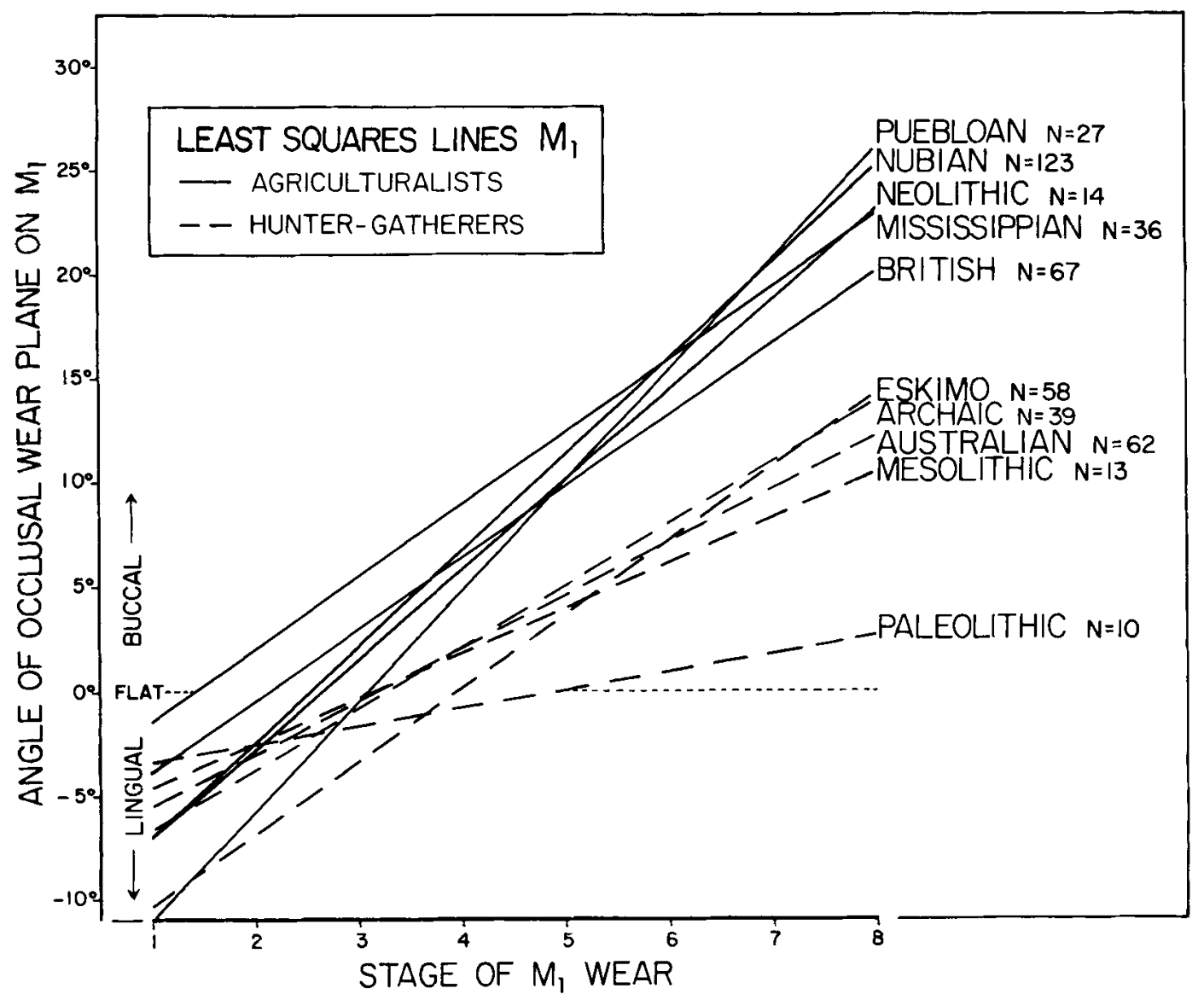

Fig. 5. Least squares lines from regression of $\mathrm{M}_{1}$ wear plane angle on stage of wear for all ten human groups. All groups begin with a lingual orientation of the crown surface that is gradually changed to the buccal with wear. Agriculturalists (solid lines) develop higher wear plane angles than hunter-gatherers (broken lines). The Paleolithic sample stands apart from recent huntergatherers, showing the flattest molar wear found in this study. 
TABLE 4. Least squares slope and intercept for $M_{1}$ angle regressed on stage of $M_{1}$ wear for agriculturalists and hunter-gatherers

\begin{tabular}{lcrrr}
\hline Group & Slope & Y-Intercept & Number & $p^{1}$ \\
\hline & & Agriculturalists & \\
Neolithic & 4.3 & -11.4 & 14 & .001 \\
Nubian & 4.2 & -11.3 & 123 & .001 \\
British & 3.4 & -7.2 & 67 & .001 \\
Mississippian & 3.5 & -7.9 & 35 & .001 \\
Puebloan & 5.3 & -16.4 & 27 & .001 \\
Overall & $4.0^{2}$ & -10.0 & 266 & .001 \\
& & & \\
Paleolithic & 1.9 & Hunter-Gatherers & 10 & .038 \\
Mesolithic & 2.1 & -4.2 & 13 & .090 \\
Australian & 2.6 & -6.7 & 60 & .001 \\
Archaic & 2.9 & -8.3 & 38 & .001 \\
Eskimo & 3.5 & -9.5 & 58 & .001 \\
Overall & $2.9^{2}$ & -13.9 & 179 & .001 \\
\hline
\end{tabular}

'Slope significantly different from zero.

${ }^{2}$ Agriculturalists are significantly different from hunter-gatherers at $p \leqslant .001$.

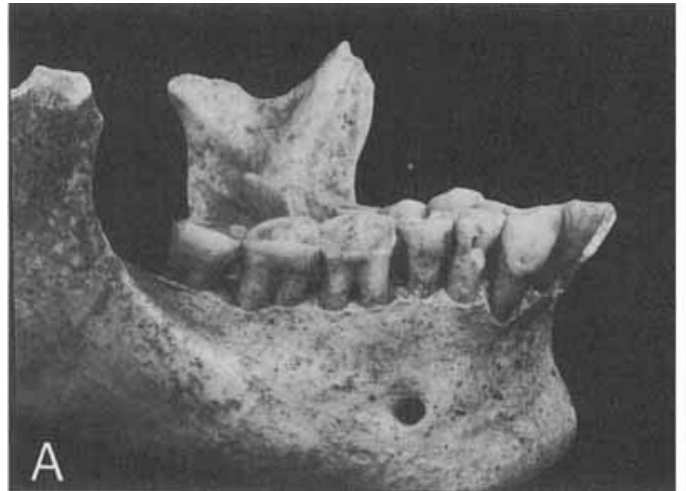

Fig. 6. Lateral views of well-worn mandibles of an agriculturalist (A) and hunter-gatherer (B) illustrating differences in wear plane angle in advanced wear. Both human first molars are at stage 7 wear, with dentin

grains or increasing thoroughness of preparation of all foods and lessening demands on the masticatory apparatus. These sample sizes are not large enough to show that the rates (regression slopes) are statistically different $\left(3.0^{\circ}, 4.0^{\circ}\right.$, and $4.7^{\circ}$ from early to late). A simple sign test suggests that the trend in mean wear plane angle is significant at $p<.05$, since 12 out of 15 pairwise comparisons of individual means are in the proper direction. These results are encouraging for the use of wear plane angles to help identify change in human subsistence. Obviously, the smaller the scale of the comparison, the larger the sample size needed.

This analysis can be applied to the entire molar dentition with similar results. Table 5

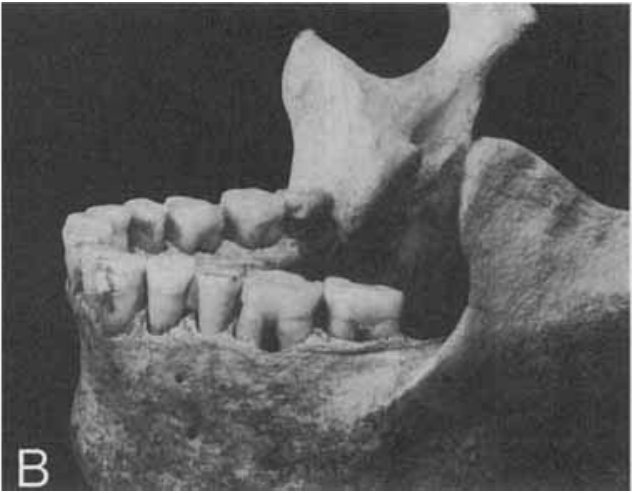

exposed on the entire occlusal surface. The agriculturalist (Nubian A-Group) shows a moderately oblique wear plane, whereas the hunter-gatherer dentition (Thule Canadian Eskimo) is worn flat.

summarizes estimates of least squares parameters and results of statistical comparison for all mandibular and maxillary molars. Agriculturalists show higher rates of change in angle at every molar tooth. Rates for M1 or M2 differ at $\mathrm{p}<.001$, but statistical significance is not reached for third molars. Sample size for third molars is greatly dimin. ished for highly worn teeth, and it is only in advanced wear that dietary differences are clearly seen.

Figure 8 illustrates overall least squares lines for the entire mandlibular arch. Molar wear stages for $\mathrm{M}_{1}, \mathrm{M}_{2}$, and $\mathrm{M}_{3}$ are staggered on the abscissa in order of eruption, although they are spread apart somewhat for clarity. Wear plane angle for each tooth is 


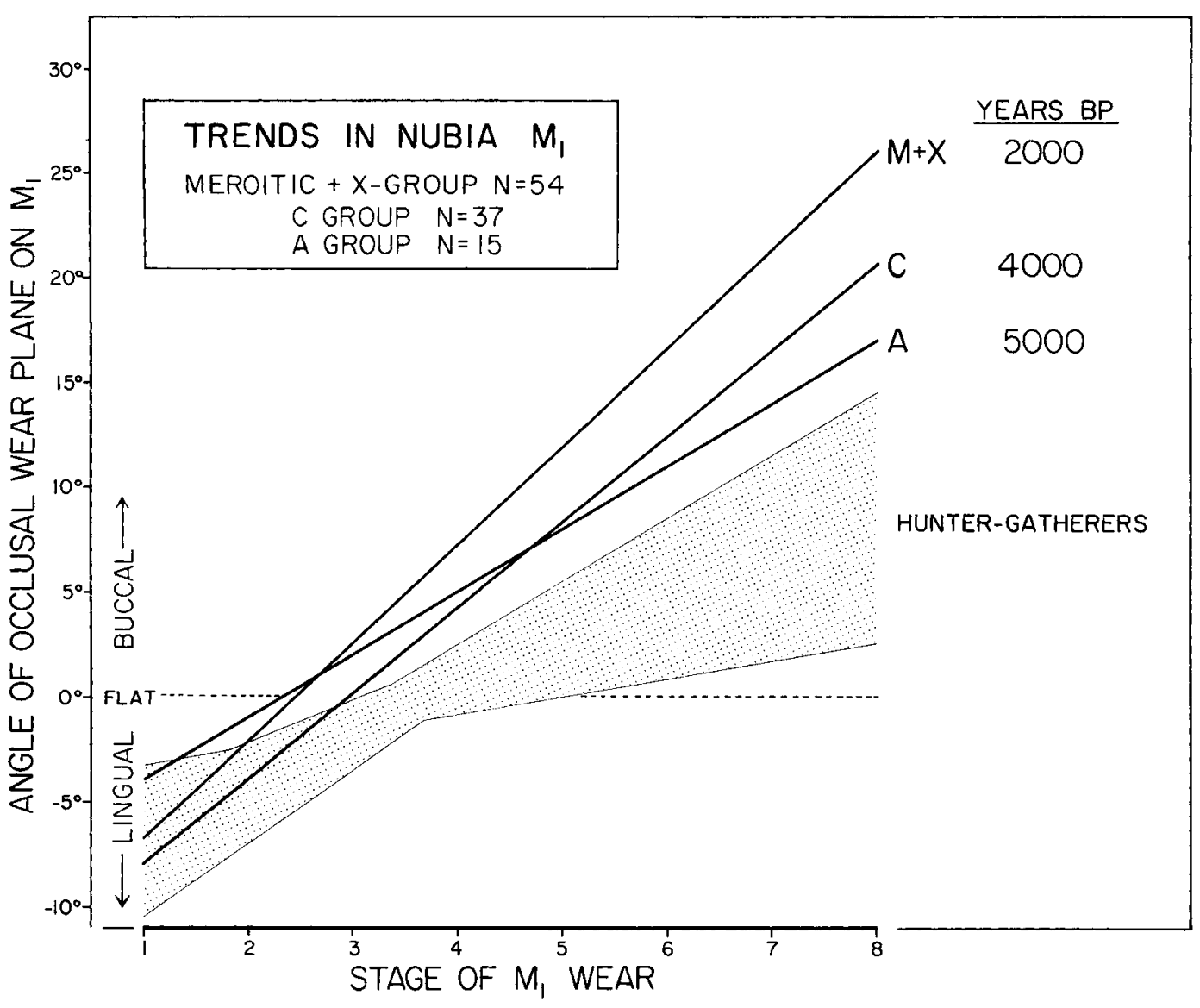

Fig. 7. Least squares lines from regression of $\mathrm{M}_{1}$ wear plane angle on stage of wear for three time periods in Nubia. Range of least squares lines (not individual data points) of hunter-gatherers is shaded for comparison. Although all three groups fall above hunter-gatherers as expected, molar wear tends to become more oblique over 3000 years. Trends in tooth wear and craniofacial robusticity should be responses to an increasing reliance on agriculture (see Carlson and Van Gerven, 1979). Although the trend is significant by a sign test, larger samples are required for reliable determination of small. scale differences in rates of change. plotted on the same scale on the ordinate. Lines are stopped at stage 7 for $\mathrm{M}_{2}$ and stage 6 at $M_{3}$ to emphasize the lack of data beyond these points. Figure 8 shows that all molars are initially inclined lingually, increasingly from $\mathrm{M}_{1}$ (ca. $-5^{\circ}$ to $-10^{\circ}$ ) to $\mathrm{M}_{2}$ (ca. $-10^{\circ}$ to $-15^{\circ}$ ) to $M_{3}$ (ca. $-15^{\circ}$ to $-20^{\circ}$ ). Since each tooth erupts at a different time, begins with a different orientation, and proceeds at its own rate of wear, surfaces of the three molars contrast in angle on a single dental arch. Each molar in a dentition is in a different phase of development of wear plane angle at one point in time. Given these sources of variability, it should be evident that the picture would be much less clear if chronologi- cal age were used as the independent variable. When each molar is sorted by its proper stage of wear, hunter-gatherers and agriculturalists differ consistently in wear plane angle.

Figure 8 is also informative on the effect of dental arch morphology on wear plane angle. This picture demonstrates that the entire molar dentition develops in similar fashion with increasing tooth wear, countering the objection that minor morphological variants can greatly change wear plane angle development. The second molar tends to have a slightly higher rate than the first (ca. $+0.4^{\circ}$ ), but this effect is not consistent across individual human groups. On closer inspection, 
the only tooth to differ much from the overall pattern is the third molar. This tooth has a slowed rate of change compared to M1 (ca. $-1.0^{\circ}$ ) in eight of the ten human groups.

Human mandibles are markedly widened at third molars, and occlusion of these teeth is slightly different (Smith, 1938b). The change in arch width relationship probably alters the path of excursion of lower cusps across upper cusps. Tooth wear tends to be more evenly distributed across the crown on third molars than it is on first or second molars.

If relative width of upper and lower arches can influence wear plane angles, can it account for the differences between huntergatherers and agriculturalists? An attempt was made to take population differences in maxillary molar overjet into account in regression analysis. Overjet was calculated for M1 and M3 as the maxillary arch width minus mandibular width. Whether $\mathrm{M}_{1}$ wear plane angles were adjusted for overjet within populations, within subsistence divisions, or for all humans, results were virtually unchanged. This factor seems to be capable of explaining no more than $2-3 \%$ of the variance in wear plane angle at first molars. The direction of differences in overjet between hunter-gatherers and agriculturalists suggests that, if anything, subsistence differences have been underestimated in the simple analysis (as in Table 5). These findings may help clarify some aspects of human mastication, but they cannot easily explain the systematic differences between huntergatherers and agriculturalists. At third molars the overjet factor becomes more important, and may explain 5-10\% of the variance in M3 wear plane angle. In general, the mandible is slightly better than the maxilla, and anterior molars are better than posterior molars for use as diet/subsistence discriminators. The mandibular first molar has the lowest variance of angle of wear plane, and the smallest species and population differences in structure of the dental arch. Furthermore, first molars always include the greatest number of teeth in the advanced wear stages that are most distinctive. Although third molars are the poorest teeth for these purposes, even these highly variable teeth show the same trend.

\section{DISCUSSION}

It was proposed that changing from a hunter-gatherer subsistence to a diet based 
more heavily on ground grains and food cooked in water has the effect of reducing food toughness, resistance, or fibrousness, leading to a reduction in masticatory forces and amount of food preparation done by the dentition. As tools increasingly take over the function of teeth, molar wear planes should become increasingly oblique. This may be an indirect effect due to a lessened lateral mandibular excursion responding to more refined foods, or a direct effect of less "puncturecrushing" mastication.

When wear plane angles are ordered by comparable stages of occlusal surface wear, consistent differences can be seen between hunter-gatherers and agriculturalists. Hunter-gatherers are the only groups to maintain relatively flat, even wear at an advanced stage of tooth wear, but even they show a slight predominance of buccal wear that steadily changes the occlusal surface angle (see Fig. 9). What seems to be a slight modification of a wear pattern adds up to a considerable difference, on the order of $8-10^{\circ}$ in advanced wear.

Portions of remaining within-group variance might be explained by differences in axial inclinations of tooth roots, maxillary arch overjet, particular dental pathologies, individual food preferences, or sex differences. Future studies could attempt to estimate the contribution of some of these factors, although large samples might be required. For example, experience with these data suggests that sex differences in human wear plane angles should not be addressed

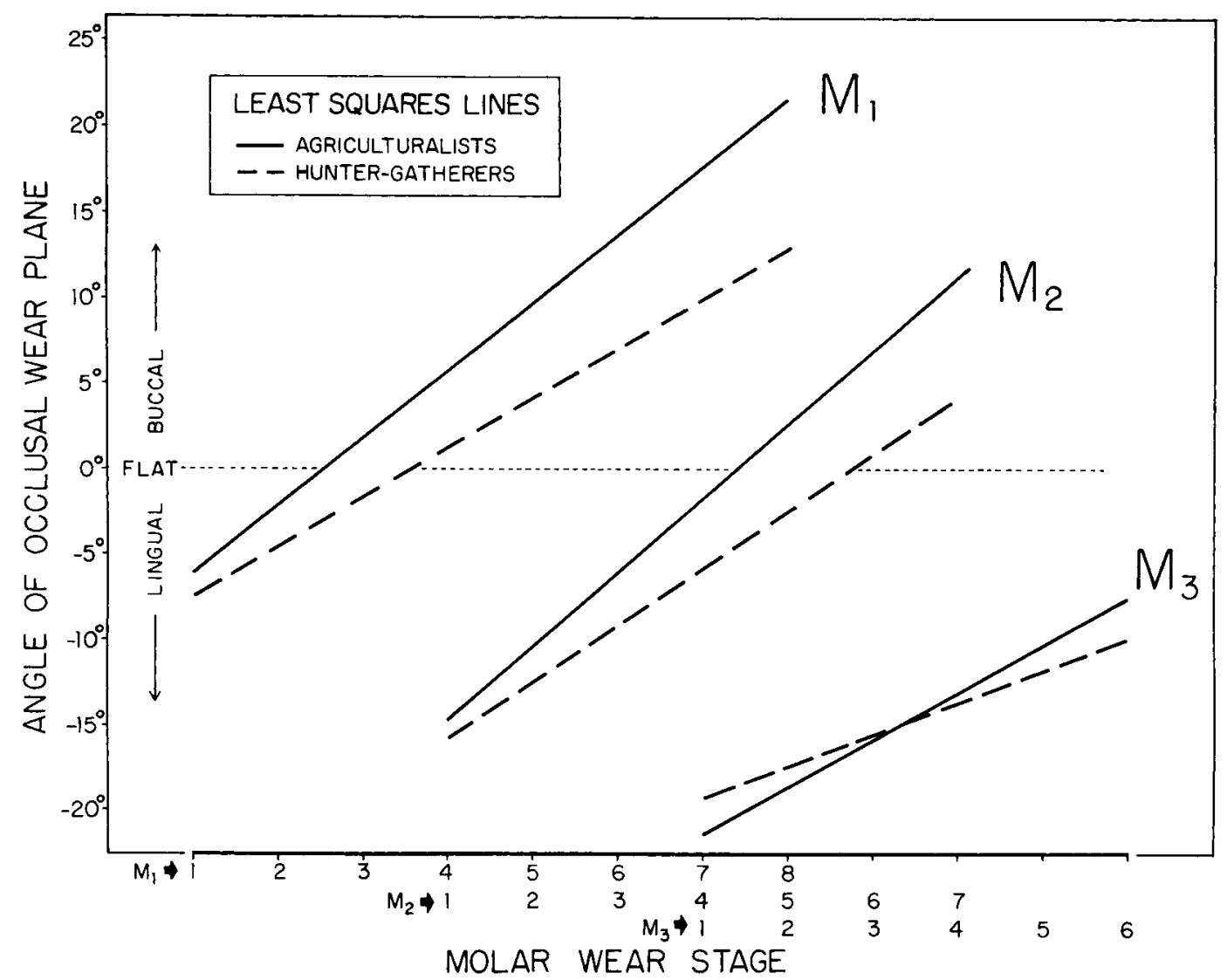

Fig. 8. Overall least squares lines from regression of wear plane angle on degree of wear for mandibular dentitions of agriculturalists and hunter-gatherers. Stages of wear for $\mathrm{M}_{1}, \mathrm{M}_{2}$, and $\mathrm{M}_{3}$ are staggered on the abscissa in order of eruption, spread apart for clarity. The three molar teeth differ primarily in y-intercept. Note that agriculturalists (solid lines) always develop higher wear plane angles than hunter-gatherers (broken lines) regardless of tooth position. 


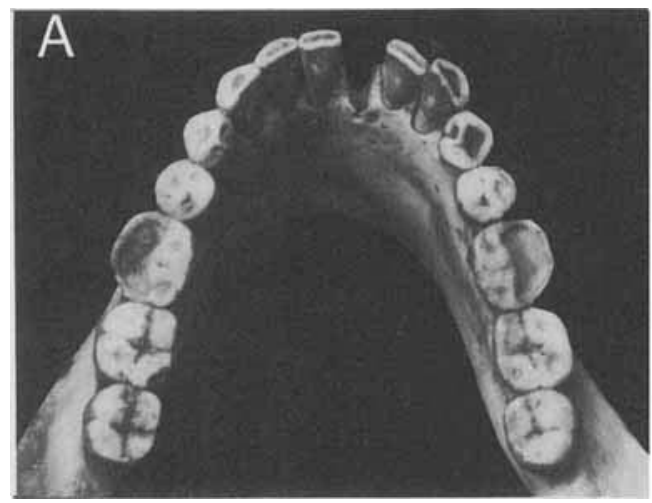

Fig. 9. Occlusal views of moderately worn mandibles showing pattern of dentin exposure on teeth of an agriculturalist (A) and hunter-gatherer (B), both with left first molars in stage 5 wear. Both mandibles show some degree of predominance of wear on buccal cusps. Note that the Nubian agriculturalist (X-Group) shows a very

without at least 40 individuals of each sex and a prior hypothesis concerning the direction of difference.

The systematic differences between hunter-gatherers and agriculturalists cannot easily be explained by morphological factors since each division covers a wide range of tooth size, tooth morphology, dental arch size, and craniofacial form. Molar wear is smilar within subsistence divisions whether agriculture is based on wheat or corn, and whether meat comes from sea mammals or marsupials. However, larger samples could clarify some smaller-scale differences.

This method would be of particular interest applied to transitional stages in the origin of agriculture. Prepottery intensive collectors of wild grains or "incipient agriculturalists" may be difficult to recognize archaeologically. In a number of cases the dates of intensive utilization of grain are being pushed back far before confirmed agriculture, as in the Middle East and Egypt (Wendorf, 1968; Reed, 1977; Kryzaniak, 1981; see also Schoeninger, 1982). Analysis of tooth wear could provide supporting evidence for change in diet or food preparation.

A change in wear plane angles should be an early sign of a change in diet in basal hominids that still show substantial morphological similarity to pongids. Early hominid tooth wear may develop in the mode of human hunter-gatherers or may show some more extreme pattern. Measurement of a cast

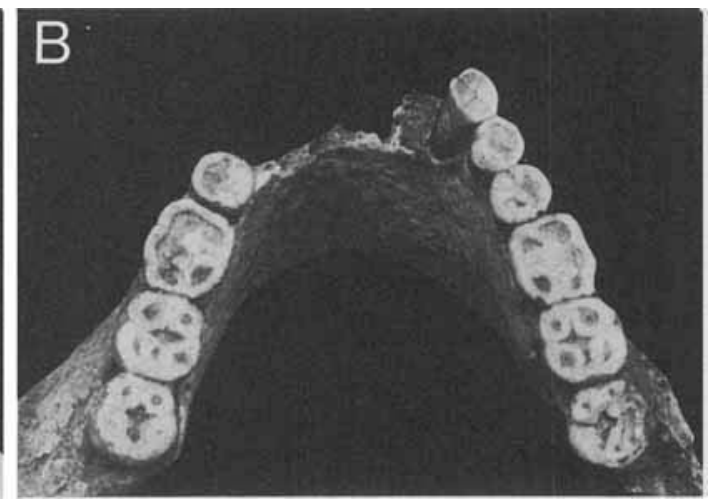

restricted pattern of wear on the first molar. The huntergatherer (Mesolithic site of Hoëdic) shows wear more evenly distributed across the crown surface. This seemingly small difference in the relative restriction of wear ultimately produces a substantial difference in angle of the occlusal wear plane.

of $\mathrm{OH} 5$ ("Zinjanthropus") gives a wear plane angle for $\mathrm{M}^{1}$ that is far outside the range of angles found in comparable human dentitions. In this case, wear is so flat with respect to the tooth axis that it appears that the original buccal angle of eruption of the tooth did not change. Hominids from Australopithecus afarensis to Homo erectus could show intriguing differences in the development of angle of molar wear planes that might give information on changes in adaptation and behavior.

\section{CONCLUSIONS}

Angle of molar wear planes can be shown to have an orderly development with increasing tooth wear on all maxillary and mandibular molars. Molar wear is more evenly dis. tributed on molars of hunter-gatherers, resulting in a relatively low wear plane angle in advanced wear. Agriculturalists show a more restricted pattern of wear and tend to develop oblique wear planes. This difference is attributed to a reduction in food toughness or fibrousness that is associated with the appearance of intensive collection of grains and intensive use of grinding stones and pottery in food preparation. This model of the relationship between food consistency and tooth wear may be tested or sharpened by applying the analysis to more human groups.

Flatness of molar wear appears to be a good indicator of change in food or food preparation. This pattern and other features of tooth 
wear can be used to support dietary inferences at important points in cultural and technological evolution in humans, and to illuminate changes in mastication and diet in earliest hominids.

\section{ACKNOWLEDGMENTS}

I would like to thank Professors Peter Andrews, Yves Coppens, James Garlick, Ole Vagn Nielsen, Jean-Louis Heim, Charles Merbs, George Romanes, Erik Trinkaus, Christy Turner, Kenneth Turner, and Douglas Ubelaker for their kind permission to study collections in their care. C. Loring Brace contributed both ideas and commentary, and John Speth, Stanley Garn, and Alphonse Burdi improved the argument. I thank Raymond Costa, Philip Gingerich, Karen Rosenberg, and two anonymous reviewers for comments on the manuscript. Karen Klitz drew the illustrations. This project was supported by grant BNS-7921733 from the National Science Foundation.

\section{LITERATURE CITED}

Ahlgren, J (1976) Masticatory movements in man. In DJ Anderson and B Matthews (eds): Mastication. Bristol: John Wright and Sons, pp. 119-130.

Black, GV (1895) An investigation of the physical characters of the human teeth. Dent. Cosmos 37:469-484.

Brace, CL (1962) Cultural factors in the evolution of the human dentition. In MFA Montagu (ed): Culture and the Evolution of Man. New York: Oxford University Press, pp. 343-354.

Brash, JC, Layard, D, and Young, M (1935) The AngloSaxon skulls from Bidford-on-Avon, Warwickshire and Burwell, Cambridgeshire, with a comparision of their principal characters and those of the Anglo-Saxon skulls in London Museums. Biometrika 27:388-407.

Broca, $P$ (1879) Instructions relative à l'étude anthropologique du système dentaire. Bull. Soc. Anthropol. Paris 2:128-152.

Butler, PM (1952) The milk-molars of Perissodactyla, with remarks on molar occlusion. Proc. Zool. Soc. Lond. 121:777-817.

Butler, PM (1973) Molar wear facets of early Tertiary North American primates. In MR Zingeser (ed): Symposia of the Fourth International Congress of Primatology, Vol. III. Basel: Karger, pp. 1-27.

Butler, RJ (1972) Age-related variability in occlusal wear planes. Am. J. Phys. Anthropol. 36:381-390.

Campbell, TD (1925) Dentition and Palate of the Australian Aboriginal. Adelaide: The Hassell Press.

Campbell, TD (1939) Food, food values and food habits of the Australian aborigines in relation to their dental conditions (parts I-V). Aust. J. Dent. 43:2-15, 45-55, 73-87, 141-146, 177-199.

Carlson, DS (1976) Temporal variation in prehistoric $\mathrm{Nu}$ bian crania. Am. J. Phys. Anthropol. 45:467-484.

Carlson, DS, and Van Gerven, DP (1979) Diffusion, biological determinism and biocultural adaptation in the Nubian corridor. Am. Anthropol. 81:561-580.

Clark, WE Le Gros (1955) The Fossil Evidence for Hu- man Evolution. Chicago: University of Chicago Press.

Clark, WE Le Gros (1967) Man-Apes or Ape-Men? The Story of Discoveries in Africa. New York: Holt, Rinehart and Winston.

Costa, RL, and Greaves, WS (1981) Experimentally produced tooth wear facets and the direction of jaw motion. J. Paleontol. 55:635-638.

Crompton, AW, and Hiiemae, K (1970) Molar occlusion and mandibular movements during occlusion in the American opossum Didelphis marsupialis. Zool. J. Linn. Soc. 49:21-47.

Dart, RA (1929) A note on the Taungs skull. S. Afr. J. Sci. 26:648-658.

Dempster, WT, Adams, WJ, and Duddles, RA (1963) Arrangement in the jaws of the roots of the teeth. J. Am Dent. Assoc. 67:779-801.

Duckworth, LHD (1898-1899) Notes on the anthropological collection in the Museum of Human Anatomy, Cambridge. J. Anat. Physiol. (Proc. Anat. Soc. G. Br. and Ireland) 33:xxiv-xl.

Ferembach, D (1974a) Les hommes de l'Épipaléolithique et du Mésolithique de la France et du nord-ouest du bassin Méditerranéen. Bull. Mem. Soc. Anthropol. Paris, Ser. 13, 2:201-236.

Ferembach, D (1974b) Le squelette Épicastelnovien de la Baume de Montclus (Gard). Bull. Mem. Soc. Anthropol. Paris, Ser. 13, 1:109-127.

Gantt, DG (1979) Patterns of dental wear and the role of the canine in Cercopithecinae. Am. J. Phys. Anthropol. $51: 353-360$.

Green, CJS (1974) Interim report on excavations at Poundbury, Dorchester, 1973. Proc. Dorset Nat. Hist. Archaeol. Soc. 95:97-100.

Greene, DL, Ewing, GH, and Armelagos, GJ (1967) Dentition of a Mesolithic population from Wadi Halfa, Sudan. Am. J. Phys. Anthropol. 27:47-56

Gregory, WK (1922) The Origin and Evolution of the Human Dentition. Baltimore: Williams and Wilkins.

Gregory, WK, Hellman, M, and Lewis, GE (1938) Fossil anthropoids of the Yale-Cambridge India expedition of 1935. Carnegie Inst. Wash. Publ. no. 495, pp. 1-27.

Grine, FE (1981) Trophic differences between 'gracile' and 'robust' australopithecines: A scanning electron microscope analysis of occlusal events. S. Afr. J. Sci. 77:203-230.

Hall, RL (1977) Functional relationships between dental attrition and the helicoidal plane. Am. J. Phys. Anthropol. 45:60-76.

Hardwick, JL (1960) The incidence and distribution of caries throughout the ages in relation to the Englishman's food. Br. Dent. J. 108:9-17.

Hayes, AC, Young, JN, and Warren, AH (1981) Excavation of Mound 7, Gran Quivira National Monument, New Mexico. Publications in Archaeology Volume 16. Washington DC: US Department of the Interior, $\mathrm{Na}$ tional Park Service.

Hiiemae, KM (1976) Masticatory movements in primitive mammals. In DJ Anderson and B Matthews (eds): Mastication. Bristol: John Wright and Sons, pp. $105-118$.

Hiiemae, KM, and Kay, RF (1973) Evolutionary trends in the dynamics of primate mastication. In MR Zingeser (ed): Symposia of the Fourth International Congress of Primatology, Vol III. Basel: Karger, pp. 28-64.

Hinton, RJ (1981) Form and patterning of anterior tooth wear among aboriginal human groups. Am. J. Phys. Anthropol. 54:555-564.

Jenness, D (1922) The life of the Copper Eskimos. Report 
of the Canadian Arctic Expedition 1913-1918, Vol. 12. Ottawa: FA Acland, pp. 5a-269a.

Jolly, CJ (1970) The seed-eaters: A new model of hominid differentiation based on a baboon analogy. Man 5:126

Keith, A (1913) Problems relating to the teeth of the earlier forms of prehistoric man. Proc. R. Soc. Med. (Odont. Sec.) 6:103-124.

Keith, A, and Knowles, FHS (1911-1912) A description of teeth of palaeolithic man from Jersey. J. Anat. Physiol. 46:12-27.

Kryzaniak, L (1981) Origin and early development of food-producing cultures in northeastern Africa. Curr. Anthropol. 22:693-694.

Leigh, RW (1925) Dental pathology of Indian tribes of varied environmental and food conditions. Am. J. Phys. Anthropol. 8:179-199.

Merbs, CF (1968) An archaeological study of the Eskimo Thule culture in the northwest Hudson Bay area. Natl. Geog. Soc. Res. Rep. 1968:247-254.

Mills, JRE (1955) Ideal dental occlusion in the primates. Dent. Pract. 6:47-61

Molnar, S (1972) Tooth wear and culture: A survey of tooth functions among some prehistoric populations. Curr. Anthropol. 34:175-190.

Moore, WJ, and Corbett, ME (1978) Dental caries experience in man: Historical, anthropological and cultural diet-caries relationships, the English experience. In NH Rowe (ed): Diet, Nutrition, and Dental Caries. Ann Arbor: The University of Michigan School of Dentistry and The Dental Research Institute, pp. 3-19.

Moses, CH (1946) Studies of wear, arrangement and occlusion of the dentitions of humans and animals and their relationship to orthodontia, periodontia, and prosthodontia. Dent. Items Interest 68:953-999.

Murphy, TR (1959a) The changing pattern of dentine exposure in human tooth attrition. Am. J. Phys. Anthropol. 17:167-178.

Murphy, TR (1959b) Gradients of dentine exposure in human tooth attrition. Am. J. Phys. Anthropol. 17:179185.

Nicholls, B (1914) A contribution to the study of the teeth of the Australian and Tasmanian aboriginals. Transactions of the Sixth International Dental Congress. London: The Committee of Organization, pp. 67-102.

Nielson, OV (1970) Human Remains: Metrical and Nonmetrical Variations. Scandinavian Joint Expedition to Nubia, Vol. 9. Copenhagen: Andelsbogtrykkeriet.

Oakley, KP, Campbell, BG, and Molleson, TI (1971) Catalogue of Fossil Hominids, Part II: Europe. London: British Museum (National History).

Pedersen, PO (1949) The East Greenland Eskimo Dentition. Meddelelser om Gronland, Vol 142, no. 3. Copenhagen: CA Reitzel.

Péquart, M, and Péquart, SJ (1934) La nécropole mésolithique de l'ile d'Hoëdic (Morbihan). L'Anthropologie 44:1-20.

Péquart, M, Péquart, SJ, Boule, M, and Vallois, H (1937) Téviec: Station-Nécropole Mésolithique du Morbihan. Paris: Institut de Paléontologie Humaine.

Pickerill, HP (1923) The Prevention of Dental Caries and Oral Sepsis. 3rd edition. London: Balliere, Tindall and Cox.

Poncins, G de (1941) Kabloona. New York: Reynal and
Hitchcock.

Prunières, D (1873) Sur les objets d'industrie contenus dans les mégalithes de la Lozère. Mat. 1873:360.

Rabkin, S (1943) Dental conditions among some prehistoric Indians of Kentucky. J. Dent. Res. 22:355-371.

Reed, CA (1977) Origins of agriculture: Discussion and some conclusions. In CA Reed (ed): Origins of Agriculture. The Hague: Mouton, pp. 879-953.

Robinson, JT (1954) Prehominid dentition and hominid evolution. Evolution 8:324-334.

Robinson, JT (1956) Dentition of the Australopithecinae. Transvaal Museum Memoir no. 9. Pretoria: Transvaal Museum.

Schoeninger, MJ (1982) Diet and the evolution of modern human form in the Middle East. Am. J. Phys. Anthropol. 58:37-52.

Schultz, AH (1925) Studies on the evolution of human teeth. Dent. Cosmos 67:935-947, 1053-1063.

Simons, EL (1968) A source for dental comparison of Ramapithecus with Australopithecus and Homo. S. Afr. J. Sci. 64:92-112.

Simons, EL (1976) The nature of the transition in the dental mechanism from pongids to hominids. J. Hum. Evol. 5:511-528.

Smith, BH (1983a) Dental Attrition in Agriculturalists and Hunter-Gatherers. Unpublished Ph.D. dissertation, The University of Michigan, Ann Arbor.

Smith, BH (1983b) Hominid attrition and occlusion at third molars: Understanding the helicoidal plane. Am. J. Phys. Anthropol. 60:255 (abstract).

Sokal, RR, and Rohlf, FJ (1969) Biometry. San Francisco: WH Freeman and Company.

Taylor, RMS (1963) Cause and effect of wear of teeth: Further nonmetrical studies of the teeth and palate in Moriori and Maori skulls. Acta Anat. 53:97-157.

Thalbitzer, W (1914) The Ammassalik Eskimo: Contri butions to the Ethnology of the East Greenland $\mathrm{Na}$ tives. Copenhagen: Biancohuno.

Turner, CG (1979) Dental anthropological indications of agriculture among the Jomon people of central Japan $X$. Peopling of the Pacific. Am. J. Phys. Anthropol 51:619-636.

Walker, AC, Hoeck, H, and Perez, LM (1978) Microwear of mammalian teeth as an indicator of diet. Science 201:908-910.

Webb, WS, and DeJarnette, DL (1942) An archaeological survey of Pickwick Basin in the adjacent portions of the states of Alabama, Mississippi and Tennessee. Bull. U.S. Bur. Am. Ethnol. 129:1-335.

Webb, WS, and Wilder, CG (1951) An Archaeological Survey of the Guntersville Basin on the Tennessee River in Northern Alabama. Lexington: University of Kentucky Press.

Wendorf, F (1968) Late Paleolithic sites in Egyptian Nubia. In F Wendorf (ed): The Prehistory of Nubia, Vol. II. Dallas: Southern Methodist University Press, pp. 791 953.

Wheeler, REM (1940) Maiden Castle, Dorset. Reports of the Research Committee of the Society of Antiquaries of London no. 12. Oxford: Oxford University Press.

Zuckerman, S (1954) Correlation of change in the evolution of higher primates. In J Huxley, AC Hardy, and EB Ford (eds): Evolution as a Process. London: George Allen and Unwin, pp. 300-353. 